\title{
Utility of GSMap Precipitation and Point Scale in Gauge Measurements for Stream Flow Modelling - A Case Study in Lam River Basin, Vietnam
}

\author{
Dang Dinh Kha ${ }^{1 *}$, Nguyen Y Nhu' ${ }^{1}$ Vu Viet Long ${ }^{2}$, Dao Thi Hong Van ${ }^{3}$ \\ 1 Department of Hydrology and Water Resources, VNU University of Science, Vietnam National University, \\ Hanoi, 334 Nguyen Trai, Thanh Xuan, Hanoi, Vietnam \\ 2 Power Engineering Consulting Joint Stock Company 1, Nguyen Trai, Thanh Xuan, Hanoi, Vietnam \\ 3 Vietnam National University, Hanoi, 334, Xuan Thuy, Cau Giay, Hanoi, Vietnam \\ * Corresponding author's e-mail: dangdinhkha@hus.edu.vn
}

\begin{abstract}
The benefit from integrating the information from multi-source was confirmed in the research of hydrologic processes in river basins. However, the use of satellite-based rainfall products in hydrologic stream flow modeling has been limited because of the perceived uncertainty associated with such data. In this study the authors presented the simulated streamflow from a SWAT model driven by merging rainfall between satellite and gauge-observed rainfall for the Lam River Basin. The results demonstrate the usefulness of merging rainfall data for stream flow modelling at a monthly time step.
\end{abstract}

Keywords: GSMaP, SWAT model, merging, Lam river basin, flow modelling

\section{INTRODUCTION}

The research on the hydrological processes in river basins benefits from a variety of rainfall products coming from remote sensing [Artan et al. 2007; Bitew and Gebremichael 2011; Khan et al. 2011]. However, the use of satellite-based rainfall estimates in stream flow modeling has been limited because of the perceived uncertainty associated with such data [Chiang et al. 2007].

It has been suggested by some researchers that using the merging method is expected to have the ability to extract the useful information from all data sources [Gebregiorgis and Hossain 2011; Nerini et al. 2015; Seo 1998; Tugrul Yilmaz et al. 2010]. However, using complex algorithms such as Bayesian merging actually may not be better than the simple algorithms even though they are relatively perfect in theory since it is difficult to meet the required assumptions [Nerini et al. 2015].

For this study, the authors selected the biascorrected coefficient since this algorithm is easy and it performs better than other commonly used algorithms. It considers the spatial variability and seasonal variations of the bias coefficient, ensures the quantitative accuracy of the entire magnitude of monthly precipitation which are confirmed as important points in the merging methods [Nie et al. 2015]. GSMap was selected since it is provided with high resolution and fairly good picture of near real time. The usefulness of merged rainfall between satellite and gaugeobserved data for hydrologic modelling was investigated in the Lam river basin.

\section{MATERIALS AND METHOD}

\section{Study sites and datasets}

The Lam River basin has the area of 27.200 $\mathrm{km}^{2}$. The flood season usually occurs in April, July to October and November on the trunk river of the Lam River and its tributaries in the middle stream and upstream. On other tributaries, 
the flood season occurs from August or September to December. A mean annual precipitation is $1,400 \mathrm{~mm}$ and the mean annual runoff is 430 $\mathrm{m}^{3} / \mathrm{s}$ at Dua station $\left(20,800 \mathrm{~km}^{2}\right)$. There are 16 rain gauges in this study area (Fig. 1). Therefore, the gauge density in the Lam river basin is 0.6 gauge $/ 1000 \mathrm{~km}^{2}$. The rain gauge networks in this study areas are low compared with the recommended minimum densities of station of World Meteorological Organization (four stations per $1000 \mathrm{~km}^{2}$ ) [WMO 2008].

\section{Datasets}

The gauged weather data for the Lam River Basin used in this study were supplied by HydroMeteorological Data Center of Vietnam (HMDC). In which, the gauged rainfall data were collected from 2 meteorological and 16 hydrological stations. Other meteorological data, such as temperature, relative humidity and wind speed were collected from 2 meteorological stations (Vinh, Ha Tinh station) located within the study area. These data were used as input to SWAT model. Figure 1 displays the location of the gauge-observed rainfall data. All data covered the period from 2010 to 2016 .
Additionally, a digital elevation model with $30 \mathrm{~m}$ resolution, the soil map scale of 1:50,000, the vegetation map scale of 1:50,000 was derived Environment and Natural resource department of Nghe An, Ha Tinh province were also provided as driver for SWAT model.

GSMaP-MVK was developed by the Japan Aerospace Exploration Agency (JAXA) Near-realtime and reanalyzed hourly precipitation products are available at $0.1^{\circ}$ spatial resolutions. These are based on both microwave and infrared satellite radiometry, combined using a Kalman filter [Ushio et al. 2009]. The authors used the daily-aggregated version of the reanalysis product from 2010-2016.

The simulated streamflow was calibrated and validated using the discharge data collected at three stations: Nghia Khanh (with an upstream area of around $4,020 \mathrm{~km}^{2}$ ), Hoa Duyet (with an upstream area of around $1,880 \mathrm{~km}^{2}$ ), Dua (with an upstream area of around 20,800 $\mathrm{km}^{2}$ ) (Figure 1), located in the Lam river.

\section{Merging method}

1. The monthly observed rainfall from 16 stations within the river basin were interpolated onto a

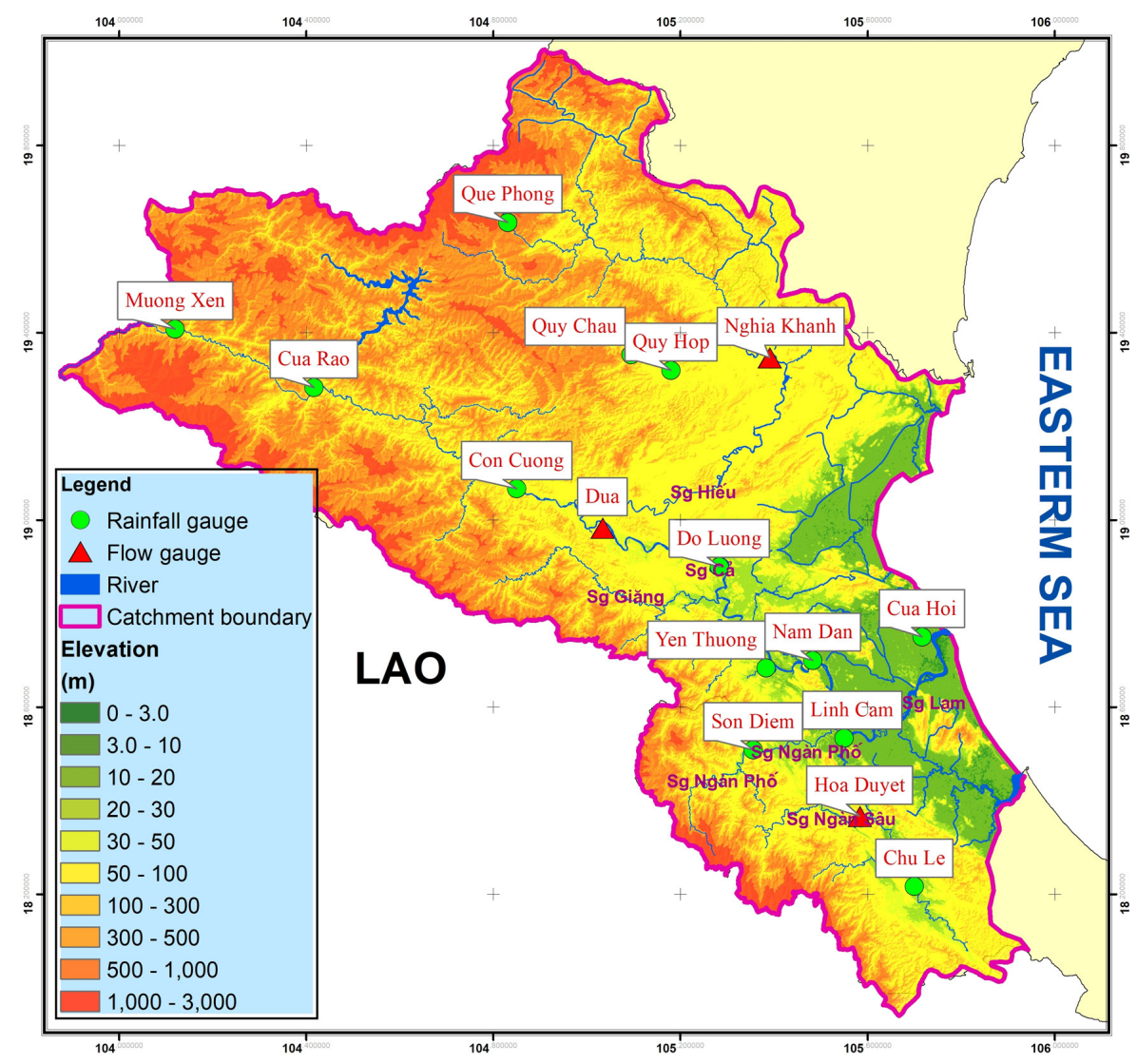

Fig. 1. The Lam river basin 
10-km grid corresponding to the grid solution of GSMap-MVK using a Universal Kriging algorithm,

2. The monthly bias- corrected coefficients were identified by matching the monthly rainfall of the GSMap-MVK and observed data over each $10 \times 10 \mathrm{~km}$ grid box [Bui and Ishidaira 2015],

3. The monthly rainfall matching procedure was calculated for 12 calendar months to consider the seasonal variations of the bias in the target data and ensures the quantitative accuracy of the entire magnitude of monthly precipitation.

4. The GSMap-Gauge merging data at the corresponding location was retrieved for daily time step by multiplying the monthly bias coefficients with daily GSMap-MVK product.

Those steps are displayed in the Figure 2 showing the diagram of how the bias-corrected coefficients of the satellite data in a grid box were obtained.

\section{SWAT model}

SWAT2012 model was used in our modeling for hydrologic simulation. SWAT is a basin-scale semi-distributed model developed by the Agricultural Research Service of the United States Department of Agriculture [Arnold et al. 2012]. SWAT requires digital elevations, land use, soils, etc. and weather information (temperature, precipitation, solar radiation, humidity, and wind speed) as input of the model. Considering the hydrologic behavior, the model provides the information on streams and rivers within the watershed under varying conditions. In this study, SWAT was used to simulate the stream flows from different rainfall products including gauge-observed rainfall, satellite (GSMap) and satellite - gauge merging product (Figure 3). SWAT is calibrated against in situ streamflow data automatically with the SWAT-CUP optimization techniques [Abbaspour 2015]. The hydrologic model is recalibrated with satellite and merging data since its usefulness was confirmed in the study of Artan $\mathrm{G}$ et al., (2007) [Artan et al. 2007]. The parameters and the default range recommended by the previous studies [Abbaspour 2015; Li et al. 2018; Ren et al. 2018; Ruan et al. 2017; Tuo et al. 2016] were first selected for sensitivity analysis and calibration in the current study.

\section{Statistic evaluations}

The visual and statistical comparisons are conducted between the simulated and observed flows, and visual comparison is conducted between satellite and observed rainfall for the whole river basin.

For the statistical "goodness of fit" of the simulated streamflows, the authors employed a commonly used measure - the Nash-Sutcliffe

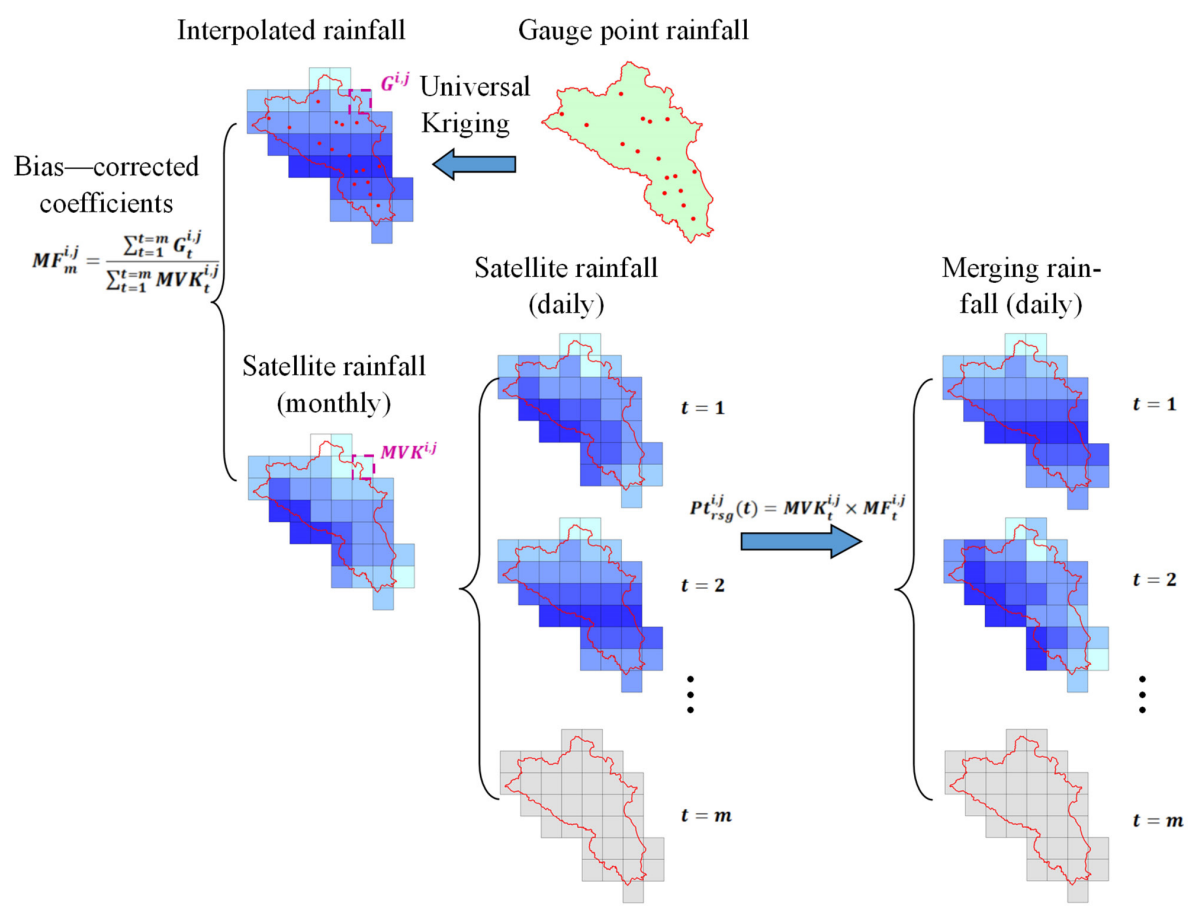

Fig. 2. The diagram of how the merging satellite-gauge are retrieved based on the bias-corrected coefficients 


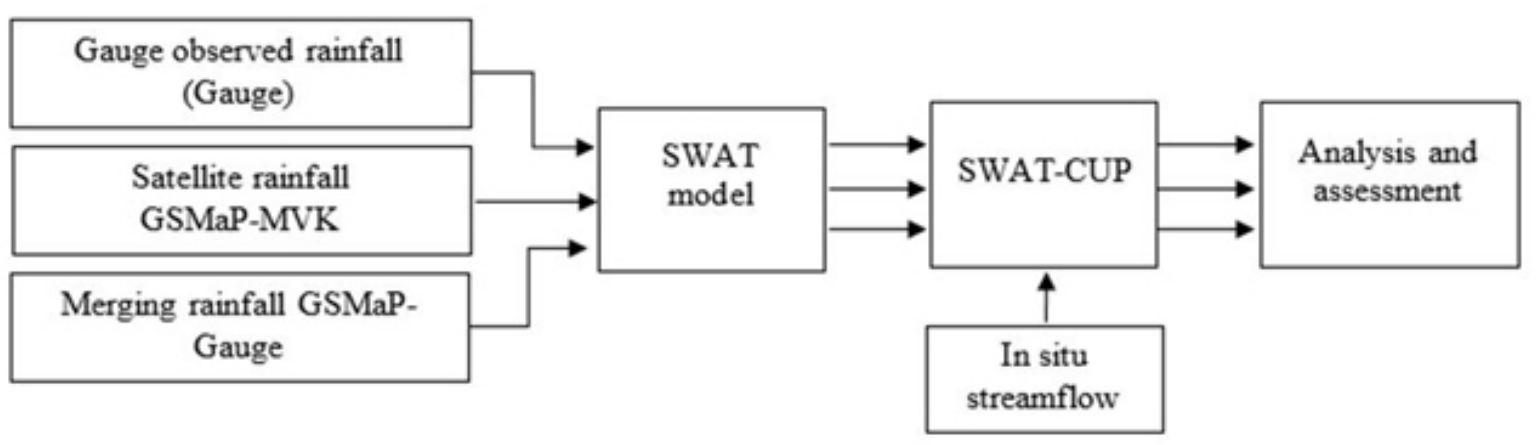

Fig. 3. General framework of the research

Coefficient of Efficiency (NSE) (Nash and Sutcliffe 1970); coefficient of determination $\mathrm{R}^{2}$, RMSE-observations standard deviation ratio (RSR) and percent bias (PBIAS) [Yuemei et al. 2007]. These statistical measures are calculated between the gauge-observed or in situ and simulated streamflow.

\section{RESULTS AND DISCUSSIONS}

In the Figure 4, the daily rainfall from gauge observation (Gauge rainfall) (Fig. 4a), GSMap satellite products (GSMap - Fig. 4b) and merging between GSMap and gauge observation (Merging rainfall - Fig. 4d) over the Lam river basin.
The datasets show the value of Sep 19, 2016. The result shows the discernable differences on the total rainfall and spatial distribution of rainfall. The Merging rainfall (Fig. 4d) kept the spatial distribution of GSMap rainfall while its total accumulated rainfall highly matched with gauge rainfall.

The SWAT model was validated with the gauge-observed streamflow (gauge streamflow) for the period from 2010 to 2016 on the Lam river basins. The hydrographs showing the simulated and observed flows of the Lam river basin at three stations are displayed in Figure 5. The graphs show that the model was able to capture the gaugeobserved hydrograph quite well when forced with gauge rainfall and merging rainfall both the timing and the magnitude of the streamflow of the
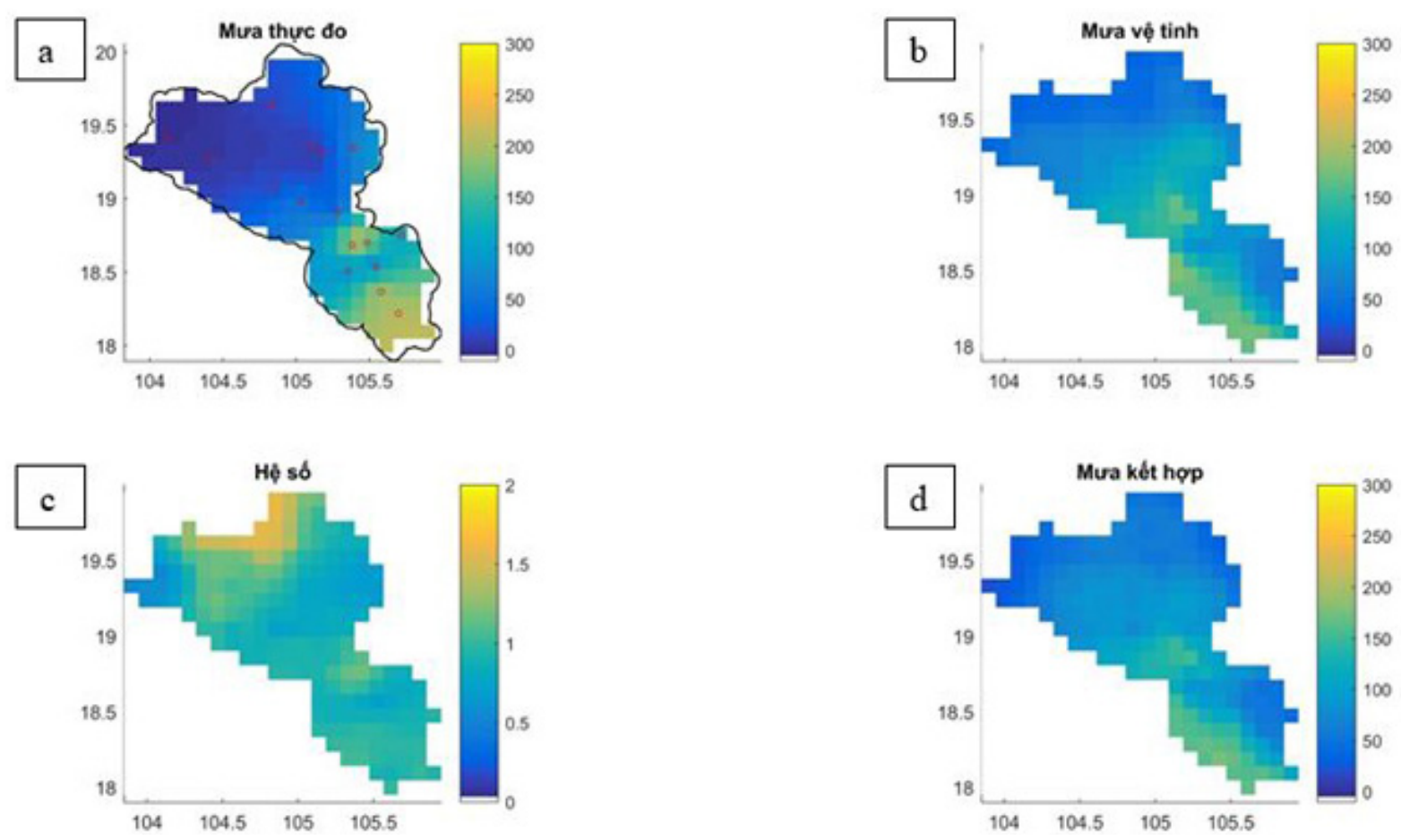

Fig. 4. Rainfall distribution on the Lam river basin (September 13, 2016) (a) gauge rainfall; (b) GSMap rainfall; (c) Corrected bias coefficients; (d) merging rainfall 


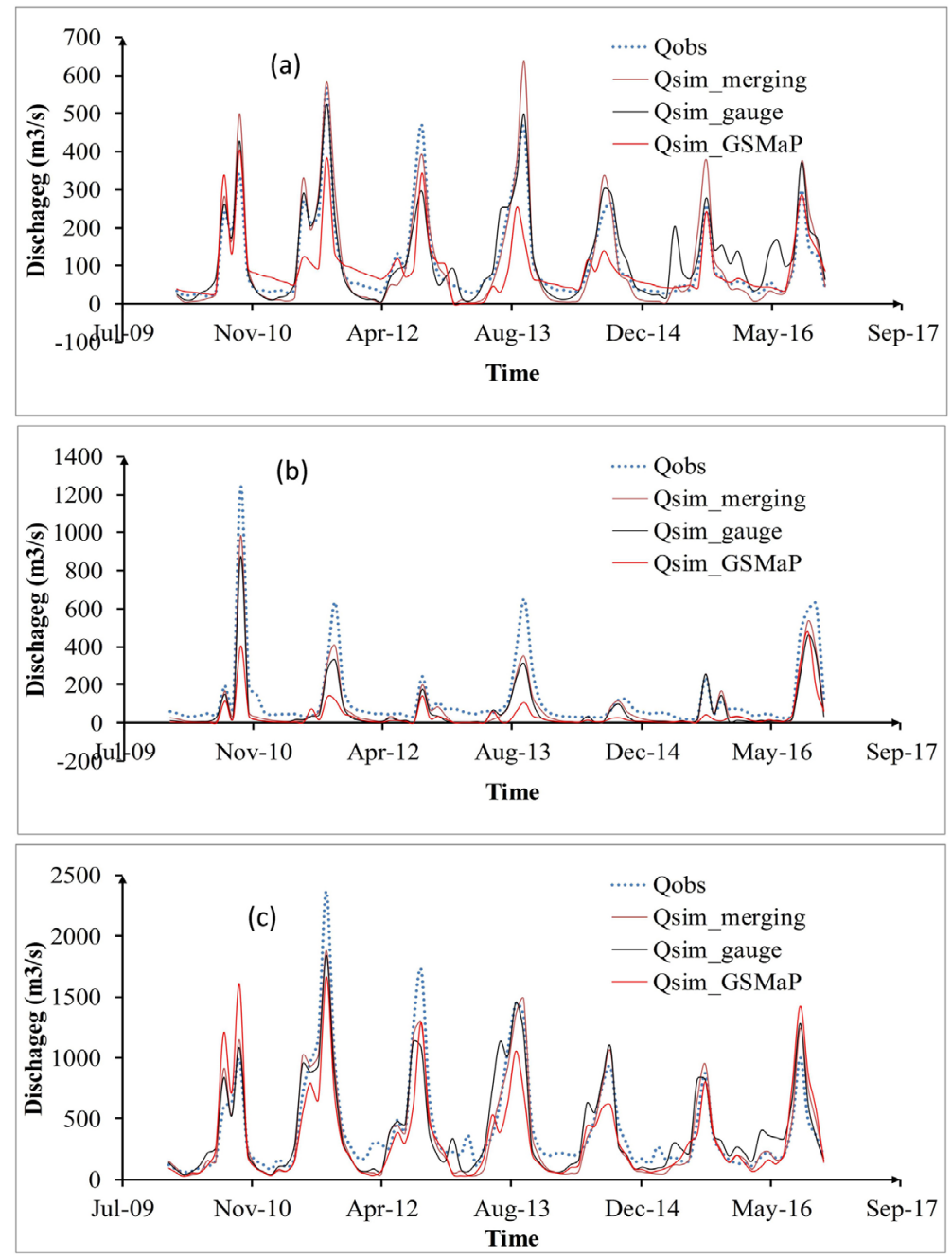

Fig. 5. Streamflow simulation obtained when the hydrologic model was forced with rain from gauge, satellite and merging method and gauge measured streamflow at: a) Nghia Khanh station, b) Hoa Duyet station, c) Dua station

basins at Dua and Nghia Khanh station with only few differences. There are large discrepancies between the observed and simulated streamflows in the Hoa Duyet which can be partly explained by the insufficiencies of gauge rainfall in the upper basin. Poor agreement is seen between streamflow forced by GSMap and gauge rainfall at all stations. It suggests that the streamflows forced by GSMap only show poor prediction.

The simulated streamflow with the model driven with the merging rainfall yields better results compared with the Simulated streamflow forced with gauge rainfall at Dua station (NSE = 0.89 and $\mathrm{NSE}=0.82)$, Hoa Duyet station (NSE = 0.84 and NSE $=0.75$ ) and has comparable results at Nghia Khanh $(\mathrm{NSE}=0.84$ and NSCE $=0.83)$.

The coefficient of determination $\left(\mathrm{R}^{2}\right)$ of the streamflow forced by gauge and merging rainfall are high from around 0.8 to 0.9 on a monthly time scale. The streamflow simulated from merging rainfall show the strongest correlation with $\mathrm{R}^{2}$ values being 0.9 to 0.94 at all three stations. The $\mathrm{R}^{2}$ coefficient is much lower at all three stations with the streamflow forced by GSMap rainfall, from 0.68 to 0.73 . These results show that the correlation for the merging rainfall is highest, and the highest is seen at the Hoa Duyet station despite the poorer rain gauge distribution in this section.

At the Dua station, the agreement between simulated streamflow forced by gauge and merging rainfall is high, with only a small PBIAS from $-2.22 \%$ to $-9.85 \%$ respectively. PBIAS was significantly large in the simulated streamflow when the hydrologic model was simulated using the GSMap rainfall, with a bias of $-19.68 \%$ (Table 1). At the Nghia Khanh station, the simulated flows forced by merging rainfall and gauge rainfall have a minor positive bias $(+0.38 \%$ and $+10.35 \%$ respectively), whereas the simulated flows forced by GSMap rainfall were significantly negatively 
Table 1. Statistical summary of the comparison between simulated streamflow forced with gauge rainfall, GSMap and merging rainfall on three stations on the Lam river basin

\begin{tabular}{|c|c|c|c|c|}
\hline \multirow{2}{*}{ Station } & \multirow{2}{*}{ Statistical index } & \multicolumn{3}{|c|}{ Rainfall data } \\
\hline & & Merging rainfall & Gauge rainfall & GSMap rainfall \\
\hline \multirow{4}{*}{ Dua } & NSE & 0.89 & 0.82 & 0.69 \\
\hline & $\mathrm{R}^{2}$ & 0.90 & 0.82 & 0.73 \\
\hline & RSR & 0.34 & 0.42 & 0.56 \\
\hline & PBIAS & $-9.85 \%$ & $-2.22 \%$ & $-19.68 \%$ \\
\hline \multirow{4}{*}{ Nghia Khanh } & NSE & 0.84 & 0.83 & 0.64 \\
\hline & $\mathrm{R}^{2}$ & 0.92 & 0.85 & 0.68 \\
\hline & RSR & 0.40 & 0.41 & 0.60 \\
\hline & PBIAS & $0.38 \%$ & $10.35 \%$ & $-16.36 \%$ \\
\hline \multirow{4}{*}{ Hoa Duyet } & NSE & 0.84 & 0.75 & 0.32 \\
\hline & $\mathrm{R}^{2}$ & 0.94 & 0.93 & 0.70 \\
\hline & RSR & 0.40 & 0.50 & 0.82 \\
\hline & PBIAS & $-39.83 \%$ & $-48.75 \%$ & $-70.35 \%$ \\
\hline
\end{tabular}

biased $(-16.36 \%)$. The overall water balance agrees to within $10 \%$ of the observed flows with the the Nghia Khanh and Dua stations. However, the simulated flows in Hoa Duyet show significantly negatively biased $-39.83 \%$ with merging rainfall and $-48.75 \%$ with gauge rainfall. This value even amplified to $-70.35 \%$ with GSMap rainfall.

These results suggested that for the Nghia Khanh station, the hydrologic model forced by merging rainfall agrees well with gauge rainfall in most of the statistical index, notably the PBIAS shows significant improvement compared with the model forced by gauge rainfall, the difference between the simulated flows forced by merging rainfall and observed flows was minimized. In contrast to the hydrologic model for Dua, high correlation but also high PBIAS are gained between the simulated and observed streamflows when compared with hydrologic model forced by the gauge rainfall.

It can be seen that the contribution of gauge observed rainfall are obviously showing better prediction for hydrological simulation, even with only one gauge observed rainfall is available and the contribution is larger with higher gauge density.

\section{CONCLUSION}

The authors have investigated the fitness of such data for streamflow modeling. The result indicates that merging rainfall between satellite and gauge-observed rainfall according to the corrected-bias coefficient provides better spatial rainfall. The gain achieved in the simulated streamflow from merging rainfall between remote sensing and gauge-observed rainfall was significant even when the number of available rainfall gauge was very low. It is therefore justifiable to suggest that merging rainfall can be used to drive hydrologic models for better streamflow prediction. However, this research has only considered one merging method and also the analysis with different time scales should be performed to give out more comprehensive picture.

\section{Acknowledgements}

This research is funded by the Vietnam National University, Hanoi (VNU) under project number QG.19.03.

The author is $\mathrm{PhD} /$ Doctoral Student under the 911 Program of VNU University of Science, Vietnam National University, Hanoi.

\section{REFERENCES}

1. Abbaspour, K.C. 2015. SWAT-CUP: SWAT Calibration and Uncertainty Programs - A User Manual, Department of Systems Analysis, Intergrated Assessment and Modelling (SIAM), EAWAG. Swiss Federal Institute of Aqualtic Science and Technol ogy,Duebendorf,Switzerland. User Manual: 100p.

2. Arnold. J. G et al. 2012. SWAT: Model Use, Calibration, and Validation. Transactions of the ASABE 55(4): 1317-35. http://elibrary.asabe.org/abstract.asp??JID= $3 \& \mathrm{AID}=42244 \& \mathrm{CID}=\mathrm{t} 2012 \& \mathrm{v}=55 \& \mathrm{i}=4 \& \mathrm{~T}=1$.

3. Artan, Guleid et al. 2007. Adequacy of Satellite Derived Rainfall Data for Stream Flow Modeling. Natural Hazards 43(2): 167-85.

4. Bitew, M. M., and M. Gebremichael. 2011. Assessment of Satellite Rainfall Products for Streamflow 
Simulation in Medium Watersheds of the Ethiopian Highlands. Hydrology and Earth System Sciences 15(4): 1147-55.

5. Bui, Thi Hieu, and Hiroshi Ishidaira. 2015. Evaluation of Satellite-Gauge Merging Precipitation Methods for Rainfall Runoff Simulations. Journal of Japan Society of Civil Engineers, Ser. B1 (Hydraulic Engineering) 71(4): I_79-I_84.

6. Chiang, Yen Ming et al. 2007. Merging Multiple Precipitation Sources for Flash Flood Forecasting. Journal of Hydrology 340(3-4): 183-96.

7. Gebregiorgis, Abebe, and Faisal Hossain. 2011. How Much Can a Priori Hydrologic Model Predictability Help in Optimal Merging of Satellite Precipitation Products? Journal of Hydrometeorology 12(6): 1287-98.

8. Khan, Sadiq I. et al. 2011. Satellite Remote Sensing and Hydrologic Modeling for Flood Inundation Mapping in Lake Victoria Basin: Implications for Hydrologic Prediction in Ungauged Basins. IEEE Transactions on Geoscience and Remote Sensing 49(1 PART 1): 85-95.

9. Li, Dan, George Christakos, Xinxin Ding, and Jiaping Wu. 2018. Adequacy of TRMM Satellite Rainfall Data in Driving the SWAT Modeling of Tiaoxi Catchment (Taihu Lake Basin, China). Journal of Hydrology 556: 1139-52. https://doi.org/10.1016/j. jhydrol.2017.01.006.

10. Nerini, Daniele et al. 2015. A Comparative Analysis of TRMM-Rain Gauge Data Merging Techniques at the Daily Time Scale for Distributed RainfallRunoff Modeling Applications. Journal of Hydrometeorology 16(5): 2153-68.

11. Nie, Suping et al. 2015. A Merging Scheme for Constructing Daily Precipitation Analyses Based on Objective Bias-Correction and Error Estimation Techniques. Journal of Geophysical Research 175(4449): 238.
12. Ren, Peizhen et al. 2018. Evaluation of Multiple Satellite Precipitation Products and Their Use in Hydrological Modelling over the Luanhe River Basin, China. Water (Switzerland) 10(6).

13. Ruan, Hongwei et al. 2017. Runoff Simulation by SWAT Model Using High-Resolution Gridded Precipitation in the Upper Heihe River Basin, Northeastern Tibetan Plateau. Water (Switzerland) 9(11).

14. Seo, D. J. 1998. Real-Time Estimation of Rainfall Fields Using Rain Gage Data under Fractional Coverage Conditions. Journal of Hydrology 208(1-2/2): 25-36.

15. Tugrul Yilmaz, M., Paul Houser, Roshan Shrestha, and Valentine G. Anantharaj. 2010. Optimally Merging Precipitation to Minimize Land Surface Modeling Errors. Journal of Applied Meteorology and Climatology 49(3): 415-23.

16. Tuo, Ye, Zheng Duan, Markus Disse, and Gabriele Chiogna. 2016. Evaluation of Precipitation Input for SWAT Modeling in Alpine Catchment: A Case Study in the Adige River Basin (Italy). Science of the Total Environment 573: 66-82. http://dx.doi. org/10.1016/j.scitotenv.2016.08.034.

17. Ushio, Tomoo et al. 2009. A Kalman Filter Approach to the Global Satellite Mapping of Precipitation (GSMaP) from Combined Passive Microwave and Infrared Radiometric Data. Journal of the Meteorological Society of Japan 87 A(June 2008): 137-51.

18. WMO. 2008. I Journal of the Nepal Medical Association Guide to Hydrological Practices. Volume I: Hydrology-From Measurement to Hydrological Information.

19. Yuemei, Hou, Zhang Xiaoqin, Song Jianguo, and $\mathrm{Na}$ Jina. 2007. Model Evaluation Guidelines for Systematic Quantification of Accuracy in Watershed Simulations. American Society of Agricultural and Biological Engineers 50(3): 885-900. 